\title{
Variations in long term wind speed during different decades in Arabian Sea and Bay of Bengal
}

\author{
V Sanil Kumar* and C Sajiv Philip \\ Ocean Engineering, National Institute of Oceanography, Goa 403 004, India. \\ *e-mail: sanil@nio.org
}

\begin{abstract}
A study has been carried out by comparing the extreme wind speeds estimated based on NCEP/NCAR reanalysis data for 100 years return period using Fischer Tippet-1 (commonly known as Gumbel) and Weibull distributions for three locations (off Goa, Visakhapatnam and Machilipatnam) in the north Indian Ocean. The wind dataset for Goa is compared with that from ERA-40 data. For higher wind speeds $\left(12-20 \mathrm{~m} \mathrm{~s}^{-1}\right)$, NCEP wind speed has higher percentage of occurrence than that of ERA-40. Analysis has shown slight upward trend in the annual maximum wind for location off Machilipatnam with an increase of $1.2 \mathrm{~cm} \mathrm{~s}^{-1}$ per year and a decreasing trend of $-1.3 \mathrm{~cm} \mathrm{~s}^{-1}$ per year in the case of Goa. The Weibull distribution with shape parameter 2 fits the annual maximum wind data better than FT-1 distribution.
\end{abstract}

\section{Introduction}

In the north Indian Ocean, most severe winds occur mainly during the monsoon periods. This monsoon has two phases namely southwest (SW) monsoon and northeast (NE) monsoon. In SW monsoon, the surface winds blow along the western coast of Indian peninsula during the months from June to November and there are some occasional occurrences of cyclones in the Arabian Sea. Another phase is in the NE monsoon in which wind blows from northeast direction along eastern coast of Indian peninsula during the months from December to May and also associated with the occurrences of cyclones in Bay of Bengal during this period. Gray (1985) found that north Indian Ocean accounts for $7 \%$ of global tropical cyclones. Dube et al (1997) found that the occurrences of tropical cyclones are more in Bay of Bengal than in Arabian Sea, and the ratio of their frequencies is about 4:1. During these periods Indian coast is vulnerable to erosion and coastal inundation due to storm surges and also it affects the offshore marine operations.
Several studies were done on a global scale and reported increase of wave heights in north Pacific and north Atlantic. Carter and Draper (1988) and subsequently, Bacon and Carter (1993) reported that the significant wave height (Hs) was increasing in north Atlantic by $3.4 \mathrm{~cm}$ per year and $2.2 \mathrm{~cm}$ per year respectively in the previous five decades. Bouws et al (1996) reported increases in the mean Hs (50th percentile) in a $5^{\circ} \times 10^{\circ}$ latitude/ longitude box in the northwest Atlantic by $2.3 \mathrm{~cm}$ per year and by $2.7 \mathrm{~cm}$ per year for a same size box in the northeast Atlantic. Similar study was done by Caires and Swail (2004) and they found a negative (decreasing) trend in the Arabian Sea as low as $-1.9 \mathrm{~cm}$ per year from the seasonal analysis during July to September. Allan and Komar (2000) and Gower (2002) reported positive (increasing) trends $(2.1 \mathrm{~cm}$ per year and $1.9 \mathrm{~cm}$ per year at the buoys 46005 and 46002) off the northwestern coast of the United States of America based on buoy measurements from American National Data Buoy Center (NDBC-NOAA) from 1978-1999.

Since winds are responsible for the generation of waves and no study has been done for the region

Keywords. Extreme value; NECP/NCAR data; north Indian Ocean; Weibull distribution; Gumbel distribution. 


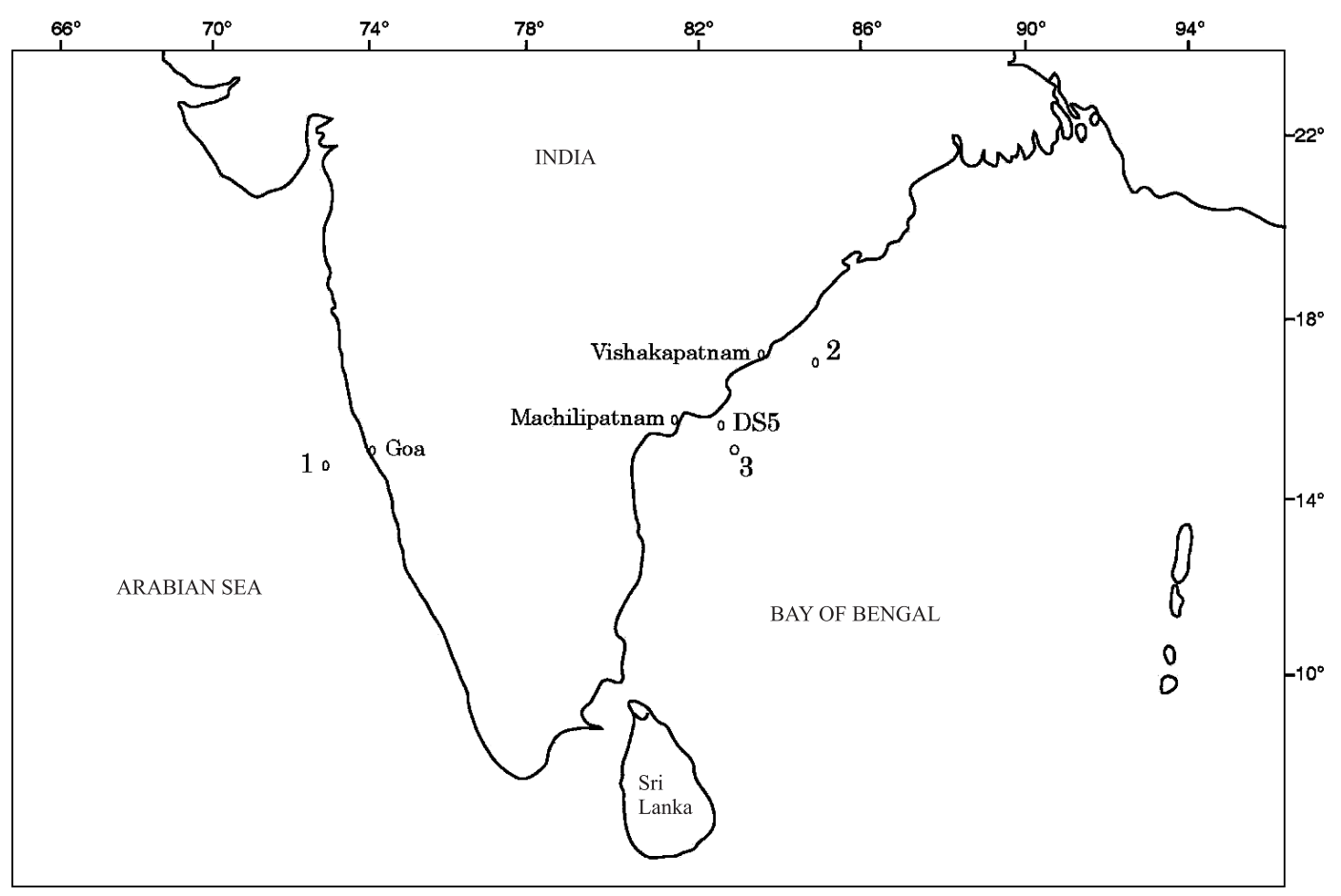

Figure 1. Map showing the study locations: Location 1 (off Goa), location 2 (off Visakhapatnam) and location 3 (off Machilipatnam).

covering the Arabian Sea and Bay of Bengal on comparison of extreme wind estimation, a study on variations in long term wind speed estimates during different decades in Arabian Sea and Bay of Bengal is carried out. For studying this, three locations are selected (figure 1). Location 1 is in the Arabian Sea (off Goa) and other two are location 2 (off Visakhapatnam) and location 3 (off Machilipatnam) in the Bay of Bengal. In Bay of Bengal, two locations are selected since the occurrence of cyclone is more in the Bay of Bengal compared to Arabian Sea. The present study consists of analyzing the extreme wind speeds starting from the investigation of decadal variability of maximum wind speeds to how this variability can affect the estimation of extreme winds. Section 2 describes the data and methodology. Section 3 explains comparison study between the datasets and also explains the analysis of extreme winds which are obtained for three locations in the north Indian Ocean with different return periods of 50 and 100 years. Conclusions are presented in section 5 .

\section{Data and methodology}

\subsection{Data}

Reanalysis data of zonal (u) and meridional (v) components of wind speed at $10 \mathrm{~m}$ height at 6 hourly intervals from ERA-40 and NCEP/NCAR were used for comparison at the location off Goa. ERA-40 reanalysis was carried out by the ECMWF using its Integrated Forecasting System (IFS) using three dimensional variational data assimilation method. It is a regular gridded data and has a spatial resolution of $2.5^{\circ} \times 2.5^{\circ}$. In order to improve the data quality, the data was assimilated from various platforms such as satellite measurements, in situ measuring systems such as drifting buoys, and from some enhancing measurements from commercial aircrafts. Thus this reanalysis data which covers the period from January 1958 to December 2000 is selected for the study. The grid covering the study locations are given in table 1 .

NCEP reanalysis data has a spatial resolution of $2.5^{\circ} \times 2.5^{\circ}$ and it is available from January 1948 to December 2006 provided by the NOAA/OAR/ESRL PSD, Boulder, Colorado, USA (http://www.cdc.noaa.gov/) was used in the long term wind speed estimation (Kalnay et al 1996). NCEP reanalysis data is compared with the moored buoy (DS5) located at $16^{\circ} \mathrm{N} ; 82^{\circ} \mathrm{E}$ off Machilipatnam (Rao and Premkumar 1998) which is maintained by Department of Ocean Development, Government of India. The buoy data consists of wind speed and direction at $3 \mathrm{~m}$ height every $3 \mathrm{~h}$ intervals. Each 3 hourly wind observation is a 10-minute average wind speed and direction sampled at $1 \mathrm{~Hz}$ by a cup anemometer with vane made by Lambercht. The accuracy of wind speed measurements is $1.5 \%$ of full scale $\left(0-60 \mathrm{~m} \mathrm{~s}^{-1}\right)$, 
Table 1. Locations and the data grid considered in the study.

\begin{tabular}{lcc}
\hline & \multicolumn{2}{c}{ Data grids $\left(2.5^{\circ} \times 2.5^{\circ}\right)$} \\
\cline { 2 - 3 } \multicolumn{1}{c}{ Study areas } & Latitude & Longitude \\
\hline Location 1 (off Goa) & $13.75^{\circ}-16.25^{\circ} \mathrm{N}$ & $71.25^{\circ}-73.75^{\circ} \mathrm{E}$ \\
Location 2 (off Visakhapatnam) & $16.25^{\circ}-18.75^{\circ} \mathrm{N}$ & $83.75^{\circ}-86.25^{\circ} \mathrm{E}$ \\
Location 3 (off Machilipatnam) & $13.75^{\circ}-16.25^{\circ} \mathrm{N}$ & $81.25^{\circ}-83.75^{\circ} \mathrm{E}$ \\
\hline
\end{tabular}

i.e., $0.9 \mathrm{~m} \mathrm{~s}^{-1}$. The data during the period from 1 May to 24 July in 2003, 2 July to 31 December in 2004 and 1 January to 31 May in 2005 were used in the study. Since the data for all months in a year is not available, the data from different years are considered for the study. The buoy data have proved to be extremely useful in validating reanalysis and satellite products (Sengupta et al 1999; Senan et al 2001). The wind speed from the buoy $\left(W_{z}\right)$ were transformed to wind speeds at $10 \mathrm{~m}$ elevation $\left(W_{10}\right)$, using Prandtl 1/7 law approximation (Streeter et al 1998) using the equation $W_{10} / W_{z}=(10 / z)^{1 / 7}$. Here $z$ is the wind measurement height of the buoy which is $3 \mathrm{~m}$.

\subsection{Methodology}

The various models adopted for fitting the longterm distribution are Fischer Tippet-1 (commonly known as Gumbel) and Weibull distributions (Issacson and Mackenzie 1981; Muir and EI Shaarawi 1986; Naess 1998). Datasets of NCEP wind speed over a period of 58 years was used for estimating the extreme value. From the wind speed data, highest value in a year was taken and the extreme value distribution of Fischer Tippet-Type 1 and Weibull were used.

Fisher Tippet-Type 1: The cumulative probability distribution function of wind speed, $P(W)$ is given below.

$$
P(W)=\exp \left\{-\exp \left[\frac{-(W-B)}{A}\right]\right\}
$$

where $A$ and $B$ are the location and scale parameter and are estimated from the data and $W$ is the wind speed.

Weibull distribution: This distribution depends on three parameters. The distribution is given below:

$$
P(W)=1-\exp \left\{-\left[\frac{(W-A)}{B}\right]^{K}\right\}
$$

where $A$ is the location parameter; $B$ is the scale parameter; and $k$ is the shape parameter.

Having established the above equations, the long term $W$ value corresponding to known $P(W)$ can be determined. These known $P(W)$ value in turn corresponding to a specified return period as given below:

$$
P(W)=1-\frac{\tau}{R_{p}}
$$

where $\tau$ is the interval between data considered and $R_{p}$ is the return period.

Having selected one distribution, it remains to estimate the parameter values which will provide the best empirical fit between the distribution and the data. The most straight forward approach is to plot the individual data points on the selected probability paper and then draw a straight line through these by eye fit. In the present case, the best-fit line is derived by the method of least squares.

\section{Results}

\subsection{Comparison of NCEP and ERA-40 data}

The wind datasets from NCEP and ERA-40 for Goa were used for the comparative study. The purpose of comparison is to find out which dataset can be considered for obtaining realistic estimate of extreme winds. The distributions of percentage of occurrences from the two datasets (figure 2A) were showing similar behaviour in moderate winds $(32 \%$ for $4-6 \mathrm{~ms}^{-1}$ and $18 \%$ for $6-8 \mathrm{~ms}^{-1}$ ) and showing dissimilar behaviour during storm winds. For storm winds the percentage of occurrence is higher for NCEP dataset compared to that of ERA-40. Parekh et al (2007) observed ERA-40 shows a good match with the moderate surface wind speed of buoys and underestimates the cyclonic wind speed and also overestimates low wind speed.

During SW monsoon periods (June to September), both datasets were showing dissimilar percentage of occurrences for each wind speed intervals (figure 2B). From the graph, both the datasets were showing maximum percentage of 

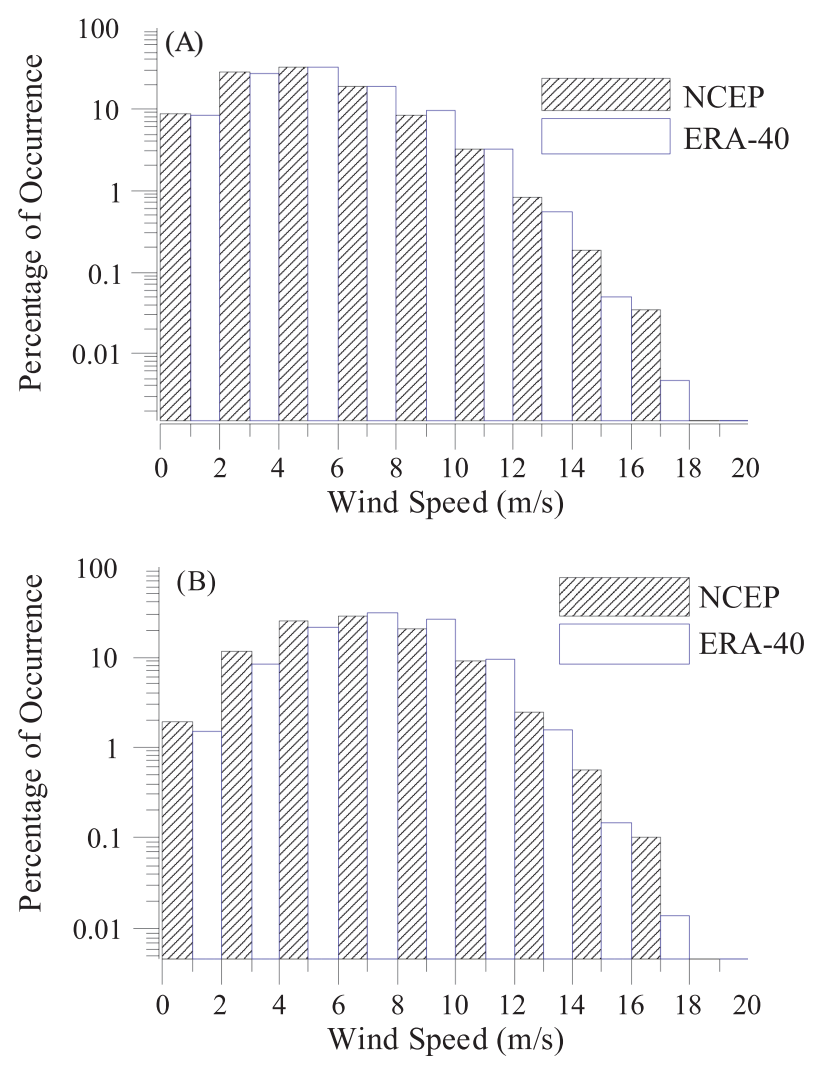

Figure 2. Graph showing the distribution of percentage of occurrence of wind speeds from NCEP and ERA-40 datasets off Goa location during 1957 to 2001. (A) represent the full data and (B) represent the SW monsoon data (June to September).

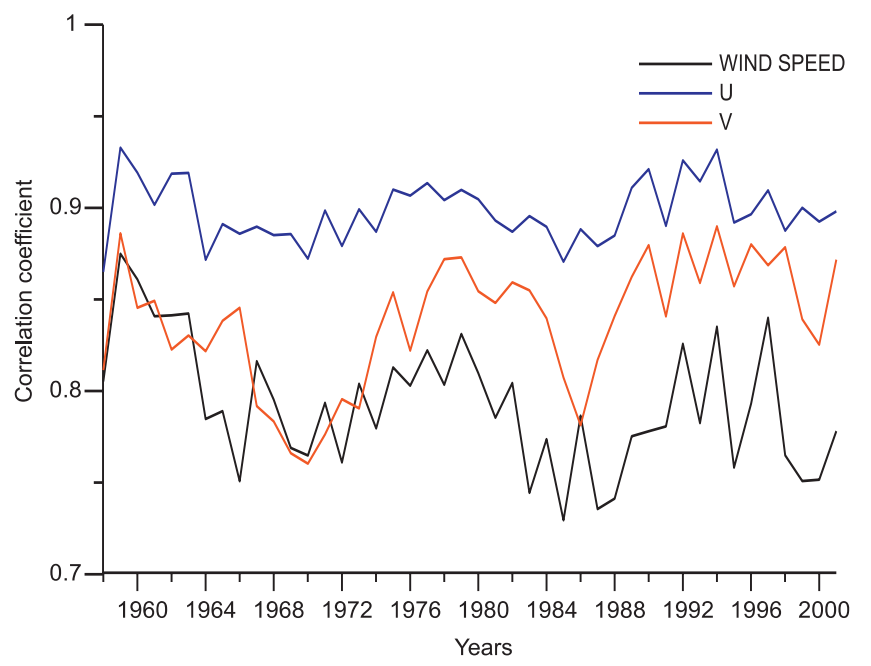

Figure 3. Graph for comparing the correlation coefficients of $\mathrm{U}, \mathrm{V}$ and wind speed from NCEP reanalysis data and ERA-40 datasets off Goa location.

occurrence for moderate winds $\left(6-8 \mathrm{~ms}^{-1}\right)$ which is observed as highest for ERA-40 (31\%) and for NCEP (28\%). For lower wind speeds $\left(2-4 \mathrm{~ms}^{-1}\right)$ and for higher wind speeds $\left(12-20 \mathrm{~ms}^{-1}\right)$, NCEP had higher percentage of occurrence than that of
ERA-40. The correlation between NCEP and the ERA-40 derived U component of wind (zonal) was 0.86 to 0.93 and that for $\mathrm{V}$ component (meridional) was 0.76 to 0.88 (figure 3 ). Wind speeds were showing relatively less correlation coefficient $(0.73$ to 0.87 ) with similar variations over the entire period from 1958 to 2000. NCEP data had higher wind speeds than ERA-40 data and NCEP dataset has longer duration of data (59 years) compared to ERA-40 (43 years), NCEP reanalysis data is used in extreme wind speed analysis.

\subsection{Comparison of NCEP and DS5 buoy data}

Goswami and Sengupta (2003) found that the mean wind speeds and intraseasonal variability are lower for NCEP reanalysis data while comparing it with Quick scat and buoy data. They found large differences in wind speed in the east equatorial Indian Ocean between NCEP reanalysis data and Quick scat data. The amplitude of daily anomalies in NCEP reanalysis was weaker and was not in phase with Quick scat anomalies in the equatorial Indian Ocean. For finding out the data reliability of NCEP reanalysis wind data, a comparison study is necessary. So NCEP wind data of Machilipatnam is compared with the available buoy data during 2003 (May-July), 2004 (July-December) and 2005 (January-May) at DS5 location off Machilipatnam (figures 4 and 5). The correlation coefficients of zonal winds (U) and the meridional winds (V) during 2004 are 0.84 and 0.68 and during 2005 are 0.68 and 0.79 , respectively. The scatter plot of 2003 buoy data and NCEP wind (figure 5A) shows correlation coefficient of 0.44 and the plot is scattered along the exact match line showing slight underestimation of wind speed. Data of 2004 (figure 5B) gives better correlation coefficient of 0.68 with underestimation of wind speed similar to that of 2003. The correlation coefficient of 2005 data was 0.51 (figure $5 \mathrm{C}$ ).

\subsection{Estimation of extreme winds for location 1}

The average SW monsoon wind speeds off Goa (location 1) was higher than the yearly average (figure 6) due to the occurrence of high winds during monsoon period (June to September) (figure 7). Low wind speeds were observed from the period 1948 to 1958 . High wind speeds were observed during the period 1959-1962 with a peak value of $18.25 \mathrm{~ms}^{-1}$ during 1961 and was the highest wind speed value occurred over the entire data period. After 1964, moderate winds were observed up to 1988 except some slack period was observed during the period from 1974 to 1978 . Two peaks of higher wind speeds were observed during $1989\left(17.5 \mathrm{~ms}^{-1}\right)$ 

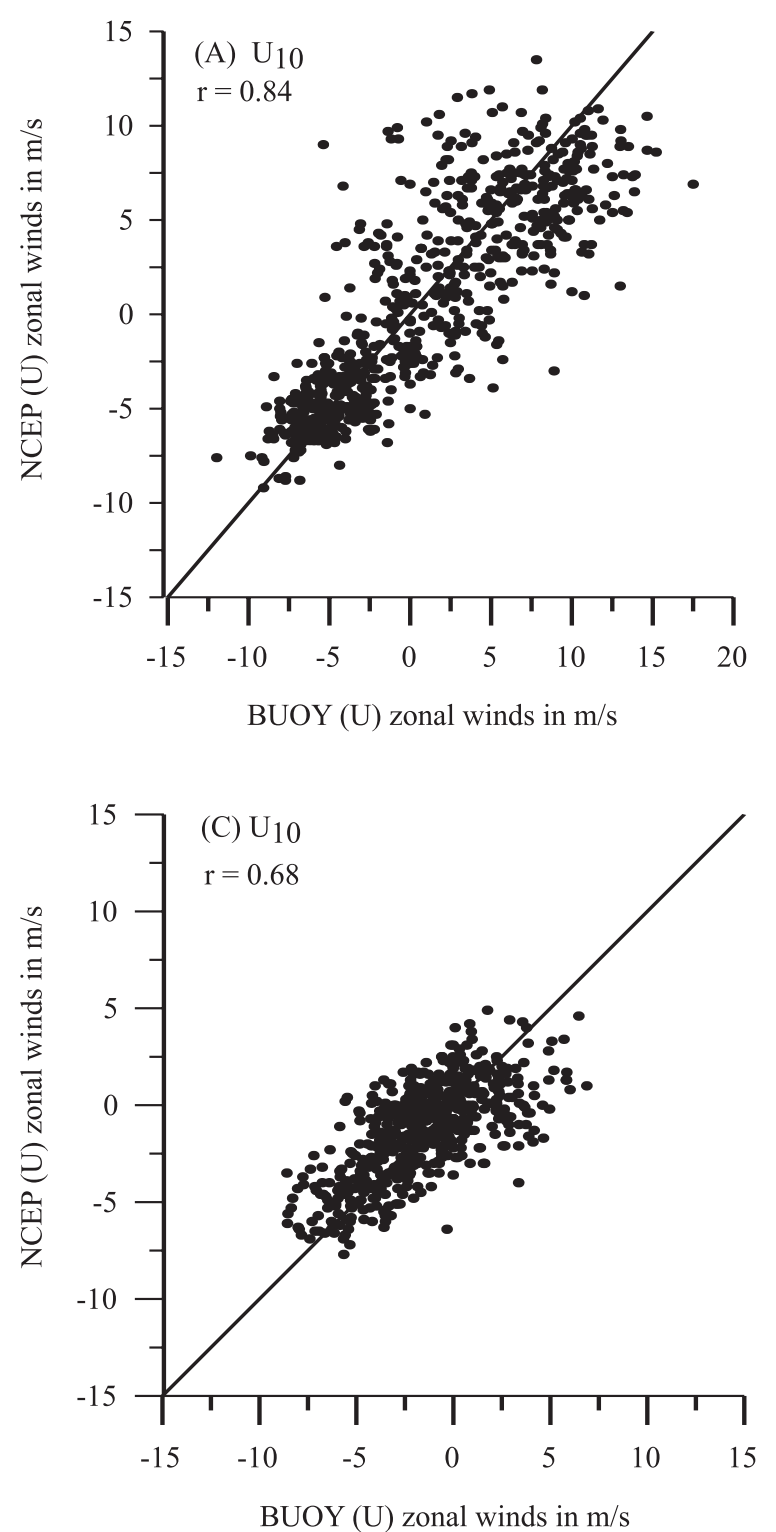

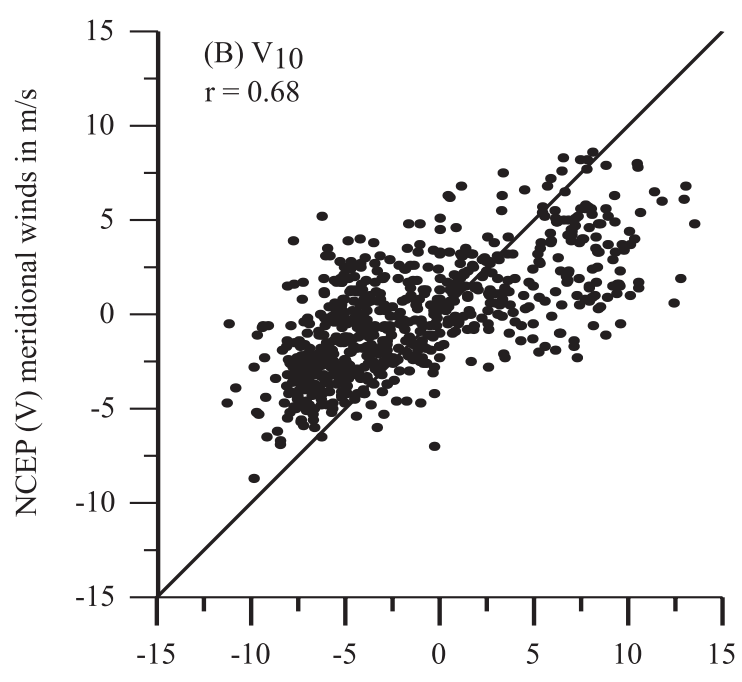

BUOY (V) meridional winds in $\mathrm{m} / \mathrm{s}$

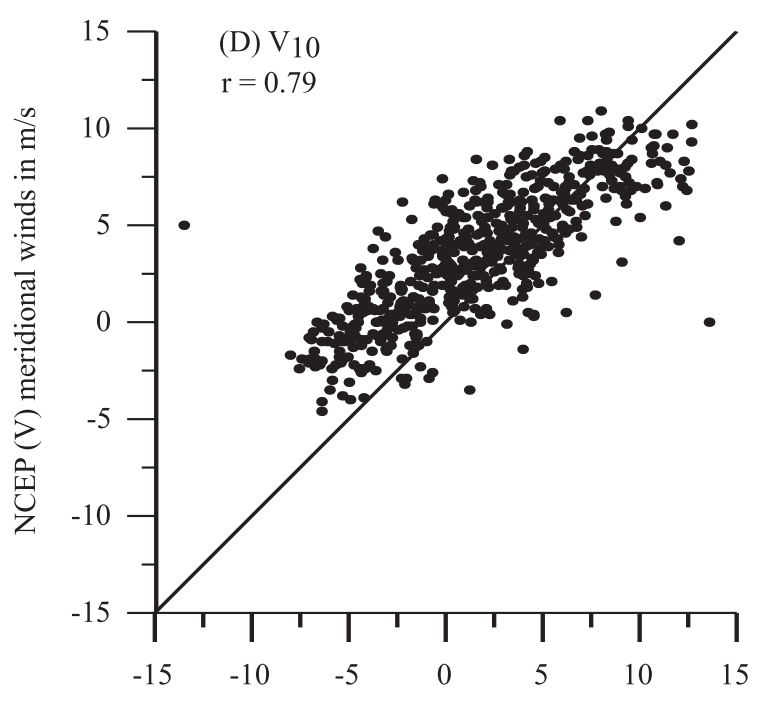

BUOY (V) meridional winds in $\mathrm{m} / \mathrm{s}$

Figure 4. Graph for comparing the zonal and meridional winds of NCEP reanalysis data and the buoy (DS5) data during the years 2004 and 2005. (A) for zonal (U) winds and (B) for meridional (V) winds during the year 2004 and (C) for zonal (U) winds and (D) for meridional (V) wind during 2005. Obtained correlation coefficients among the variables are given in each panel.

and $1996\left(17.98 \mathrm{~ms}^{-1}\right)$. While observing the variability during individual periods of 10 years, it was found that yearly maximum winds were lowest for the period 1948 to 1958 compared to other periods. This was due to the low monsoon wind speeds occurred during that period. During 1968-1978 and 1978-1988 moderate winds were observed. During the last decade (1988-1998) two peaks of high wind speeds were occurred during the years 1989 and 1996 and these peaks were during the monsoon period. There was no significant upward trend in wind speed, instead a decreasing trend $\left(-1.3 \mathrm{~cm} \mathrm{~s}^{-1}\right.$ per year) was observed at location 1. Singh et al (2001) observed a slight negative (decreasing) trend in annual cyclone frequency over Arabian Sea during the months of June and September. This negative (decreasing) trend might be due to reducing frequency of cyclones during monsoon season in this region.

Different epochs $(K)$ taken for extreme wind estimation were $10,20,30,40$ and 50 years. The distributions of FT-1 and Weibull schemes $(k=2)$ that are having high correlation coefficient and least square of residuals were selected for the analysis. Extreme wind speed value of $17.89 \mathrm{~ms}^{-1}$ (table 2) for the 10-year data (1948-1958) was due to the low wind speeds occurred during this period (figure 6$)$. High value $\left(21.38 \mathrm{~m} \mathrm{~s}^{-1}\right)$ for the 

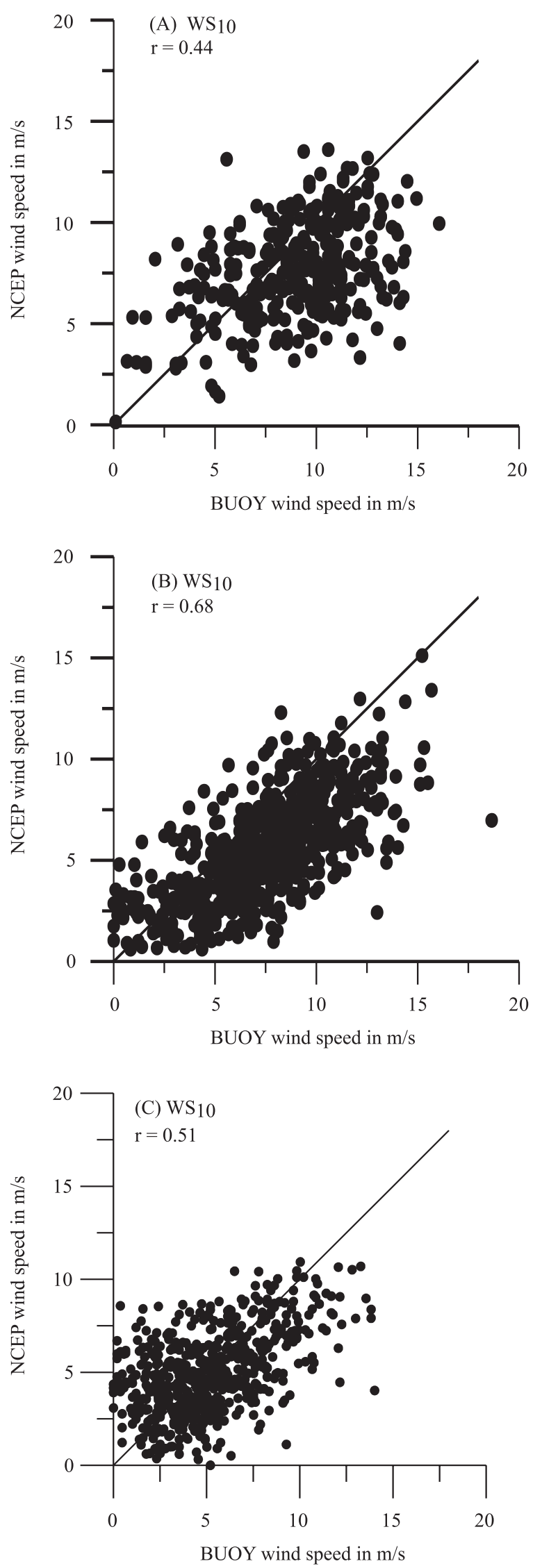

Figure 5. Graph comparing the wind speed of NCEP reanalysis data and buoy (DS5) data during the years 2003(A), 2004 (B), 2005 (C) along with obtained correlation coefficients.
1958-1968 was due to the highest wind speed $\left(18.25 \mathrm{~m} \mathrm{~s}^{-1}\right)$ occurred in the year 1961. Similarly for the remaining periods, the obtained extreme values were showing high and low fluctuations with respect to the variation in maximum wind speed. This feature was also visible for longer epochs of 20, 30, 40, and 50 years. The successful application of the AM method requires many years of data, say, at least 30 years (Pugh 1987). The obtained extreme values for the longest data blocks (19481988), (1958-1998) and (1948-1998) that are having $3 K$ values greater than 100 can be considered as reliable estimates and so the corresponding wind speeds were 19.5, 19.79 and $19.63 \mathrm{~m} \mathrm{~s}^{-1}$ for return period of 100 years (table 2).

The extreme values estimated using Weibull distribution was exhibiting similar behaviour as that of FT-1 distribution (figure 8). The obtained wind speeds with 100-year return period were 18.79, 19.08 and $18.91 \mathrm{~m} \mathrm{~s}^{-1}$, respectively for the data periods of 1948-1988, 1958-1998 and 1948-1998 (table 2). The fit of Weibull distribution with $k=2$ to the dataset (1948-1998) was better than that of FT-1 distribution. Since the correlation coefficients of Weibull scheme has better correlation coefficient (0.94 to 0.99) and least square of residuals (0.02 to 0.11), whereas FT-1 scheme has lower correlation coefficient (0.91 and 0.99) and larger square of residuals (0.02 to 0.15) (table 3 ). Hence the estimates from the Weibull scheme can give better estimation of extreme winds than FT-1 scheme.

The percentage differences between the extreme values estimated for longer duration data (50 years) and that estimated for shorter durations were examined to find out how much extent, the estimated extreme value of shorter terms deviates from the estimated extreme wind speed based on longer duration data. The obtained percentage differences between the first four epochs (of 10 years interval) and long-term period were showing high variations (table 4). The negative values correspond to lower wind speeds and the positive values correspond to higher wind speeds. For the longer term epochs (20, 30 and 40 years) percentage differences were showing similar variations as above their short term epochs. While looking through the percentage differences for different return periods for each epoch, there can be seen that the percentage differences were not a constant but varying for each epoch. The variations were getting lower with long-term data signifying the importance of considering data of long duration in estimation of extreme value.

\subsection{Estimation of extreme winds at location 2}

The location 2 is located off Visakhapatnam in the Bay of Bengal. Higher wind speeds were 

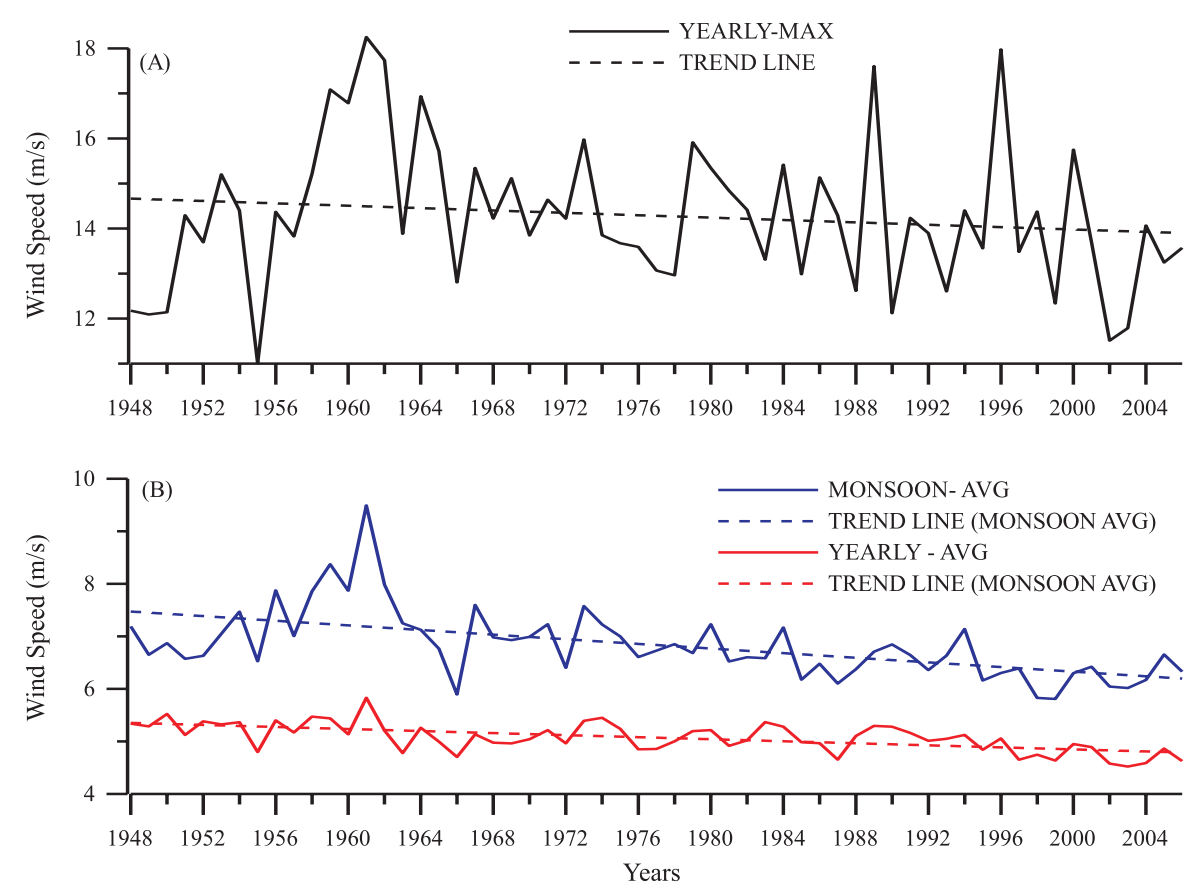

Figure 6. Graph showing interannual variability of (A) yearly maximum wind speed and (B) average monsoon wind speed and the yearly average wind speed for the location off Goa.

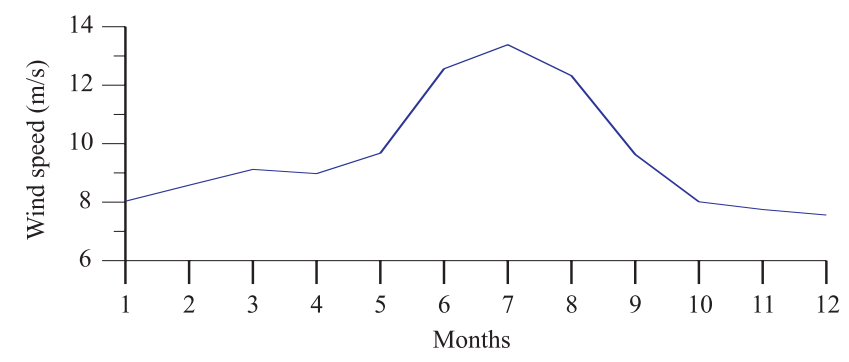

Figure 7. Graph showing the monthly average wind speeds.

observed at this location (figure 1) during both SW monsoon period (June to November) and NE monsoon period (December to May). Low wind speed was observed during 1948 to 1955 which was similar to location 1. After 1955, high speed winds ( 15 to $17 \mathrm{~m} \mathrm{~s}^{-1}$ ) were prevailed throughout the years during 1958-1964, 1966-1970, 1972-1975, and 1991-1996 (figure 9) with highest wind speed of $20.3 \mathrm{~m} \mathrm{~s}^{-1}$ in 1993 . Average of yearly maximum wind speed was $16.4 \mathrm{~m} \mathrm{~s}^{-1}$. There was no decreasing or increasing trend in the yearly maximum wind speed at Visakhapatnam.

The estimated extreme value for epoch (19481958) based on FT-1 distribution is $19.1 \mathrm{~m} \mathrm{~s}^{-1}$ for the return period of 100 years. This period was observed as the occurrence of the lowest wind speeds. For the next year periods, the estimated winds were above $20 \mathrm{~m} \mathrm{~s}^{-1}$. The extreme winds were higher than that in the case of Goa. Maximum estimated wind speed of $22.73 \mathrm{~m} \mathrm{~s}^{-1}$ was observed during the period 1968-1978 due to the high winds that were frequently occurred at this region. For the long term epochs (1948-1988), (1958-1998), (1948-1998), the estimated values of wind speed with 100-year return period were 21.06, 21.52 and $21.22 \mathrm{~m} \mathrm{~s}^{-1}$, respectively.

A significant feature observed in the case of Weibull distribution over the FT-1 distribution was the good fitting with the data (figure 10). Cook and Harries (2001) found that both Generalized Pareto Distribution and Weibull methods were better than standard Gumbel analysis of annual maxima and compensate for variation in the annual population of the extremes found in the real observations. The extreme wind speed obtained for the longest term (1948-1998) was $20.44 \mathrm{~m} \mathrm{~s}^{-1}$. Compared to the data of location 1, good correlation coefficient was found for the data at location 2 in the case of Weibull distribution.

\subsection{Estimation of extreme winds at location 3}

The location 3 is off Machilipatnam in the Bay of Bengal (figure 1). This region is also subjected to high storms similar to location 2 . For the first 10-year periods (1948-1958), two peaks of high wind speeds were observed during the years 1950 and 1953 and low wind speeds were observed during 1949 (figure 11). These peak values were not much affected by the low average monsoon winds that had occurred during this period. High wind speeds were observed during the period from 1957 to 1962 with highest peak $\left(19.9 \mathrm{~m} \mathrm{~s}^{-1}\right)$ in the year 1962. This period was noted for the period of 


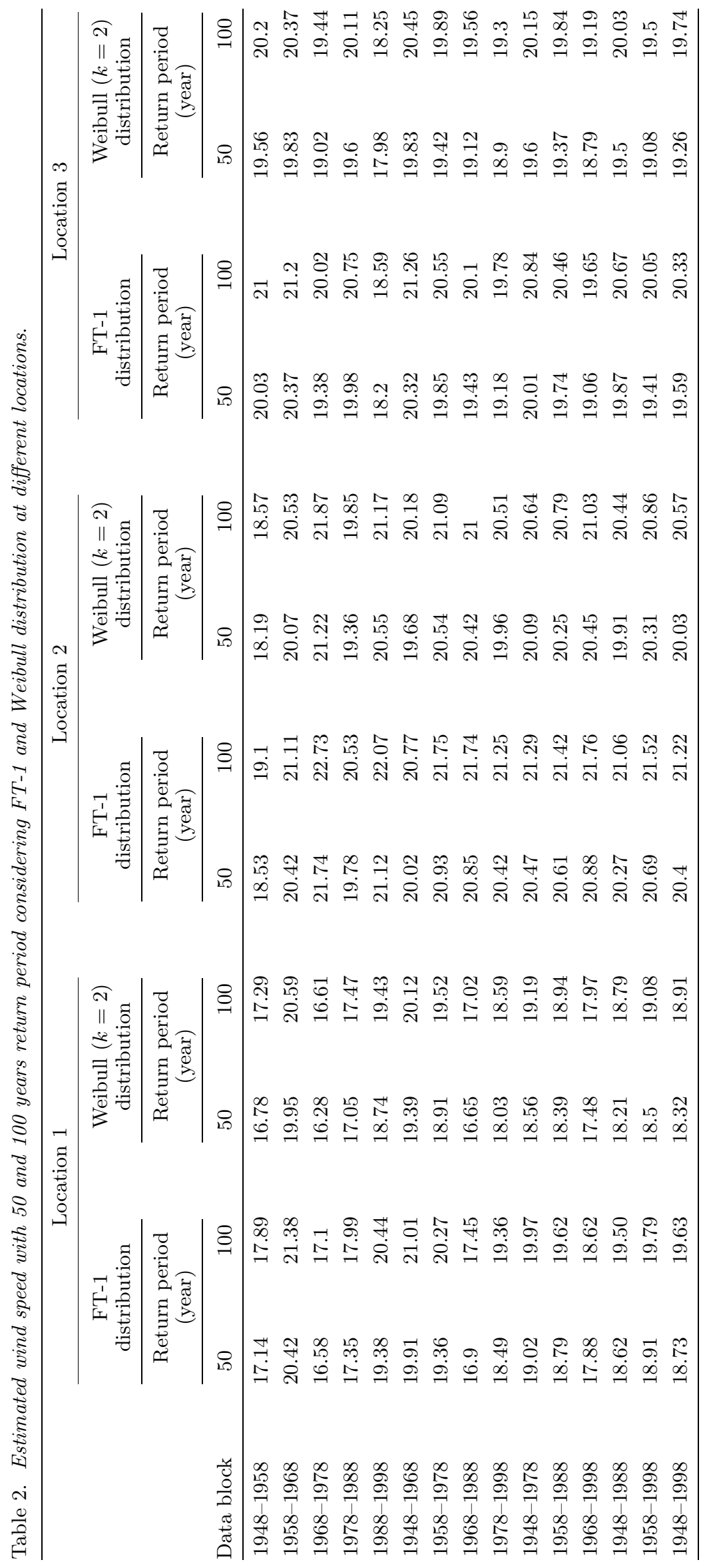



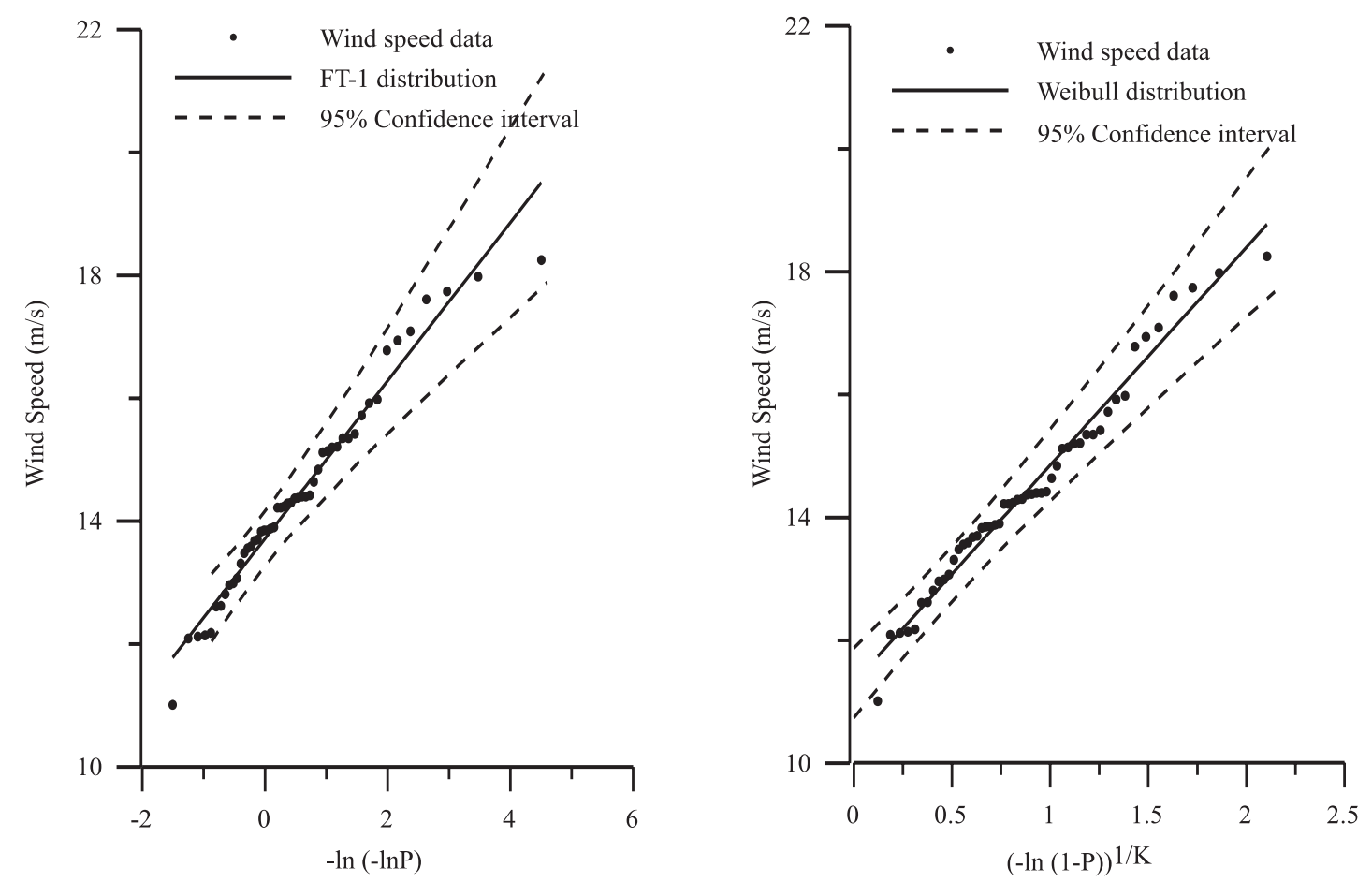

Figure 8. FT-1 and Weibull $(k=2)$ distributions applied to the yearly maximum wind data during 1948 to 1998 for the location off Goa.

frequent high wind speed and the corresponding monsoonal winds were also higher. This period was followed by the period of low wind speeds from 1963 to 1968. During the next period (19681978), low wind speeds were observed in the early period and followed by alternatively occurring high wind speeds ranging in between 16.8 and $18.3 \mathrm{~m} \mathrm{~s}^{-1}$. These alternative occurrences of wind speeds were also observed during the period 1979 to 2004, except for the period 1994 to 2000. During 1988-1992, major contribution of maximum wind speeds was from the corresponding monsoon winds occurred. In general, while observing the maximum wind speeds a gradual increasing trend is observed. This increasing trend was estimated as $1.2 \mathrm{~cm} \mathrm{~s}^{-1}$ per year. This feature was absent for the other two locations (off Goa and off Visakhapatnam). Even though NCEP underestimates the cyclone winds, the increasing trend in wind speed was due to the increase in the frequency of cyclones crossing the location 3. Singh et al (2001) observed a positive trend in annual cyclonic frequency in the north Indian Ocean and which was prominently contributed by increasing trend in frequency of occurrences in the Bay of Bengal. They also observed major cyclone occurring months during a year as November and May in north Indian Ocean and also estimated the increasing trend as +0.67 per 100 years for November cyclone frequency and +0.27 per 100 years for May cyclone frequency.
During the epoch 1948-1958, the estimated extreme wind speed with return period of 100 years following FT-1 distribution was $21 \mathrm{~m} \mathrm{~s}^{-1}$ (table 2). This high value corresponds to the peak wind speeds occurred during the years 1950 and 1952 (figure 11). For the next epoch 1958-1968, the obtained extreme wind speeds were also high $\left(21.2 \mathrm{~m} \mathrm{~s}^{-1}\right)$ which were influenced by highest peak wind $\left(19.9 \mathrm{~m} \mathrm{~s}^{-1}\right)$ in 1962 . The extreme wind for 1968-1978 data block was $20.75 \mathrm{~m} \mathrm{~s}^{-1}$. This was because of maximum wind speeds of late 1960 dominate over the low wind speeds of early 1960 . The extreme values for the epochs 1948-1988, 1958-1998 and 1948-1998 were 20.67, 20.05 and $20.33 \mathrm{~m} \mathrm{~s}^{-1}$, respectively.

The Weibull distribution with $k=2$ (figure 12) was showing best data fitting among all other distributions. The estimated wind speed with return period of 100 years covering 1948-1958 was $20.2 \mathrm{~m} \mathrm{~s}^{-1}$, much lower to the corresponding FT-1 value. Other values were also showing lower to the estimated values to that of FT-1. Estimated extreme values for the longest terms (40 and 50 years) of epochs 1948-1988, 1958-1998 and $1948-1998$ were $20.03,19.5$ and $19.74 \mathrm{~m} \mathrm{~s}^{-1}$, respectively. For location 3, both the Weibull $(k=2)$ distribution and the FT-1 distribution fits the data better (figure 12 and table 3 ).

The location parameter (B) is decreasing as the scale parameter (A) is increasing (figure 13). Monahan (2006) found that the shape parameter 


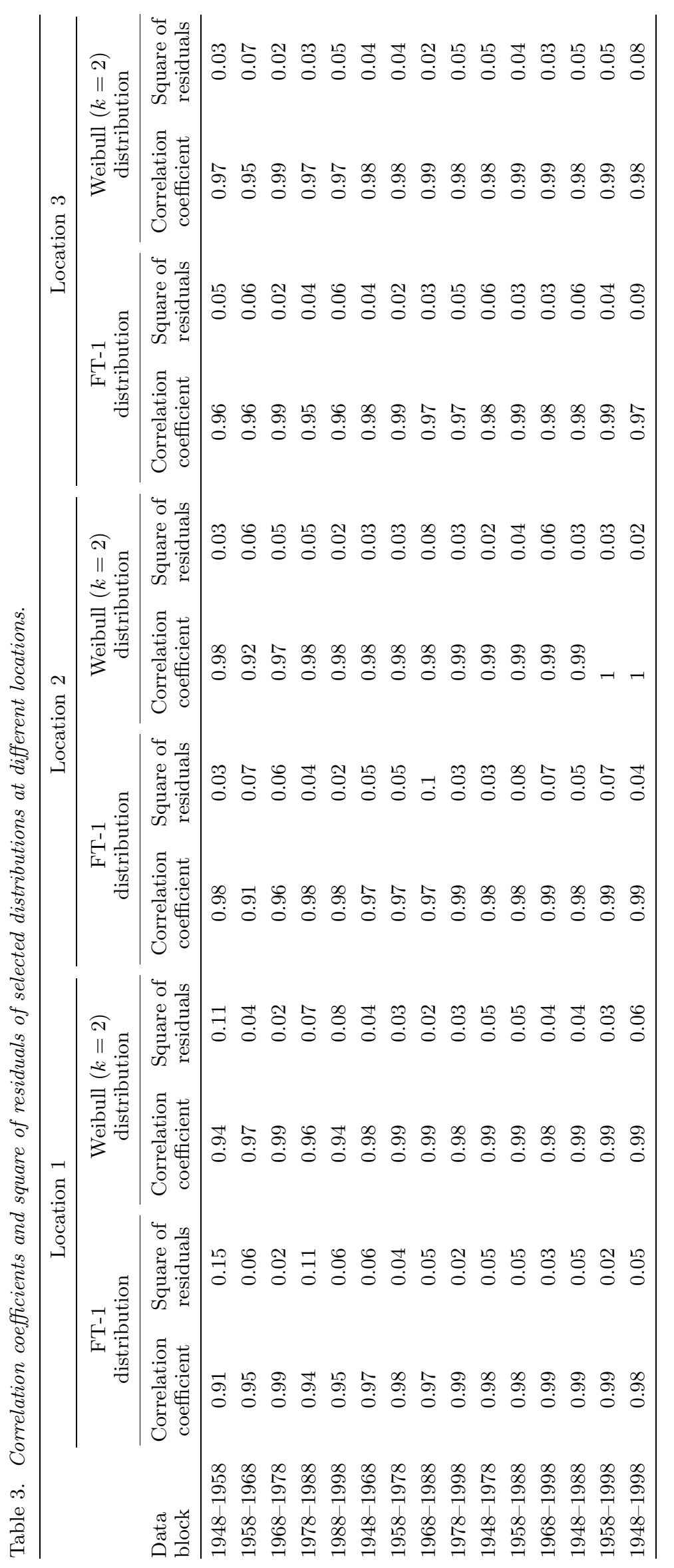




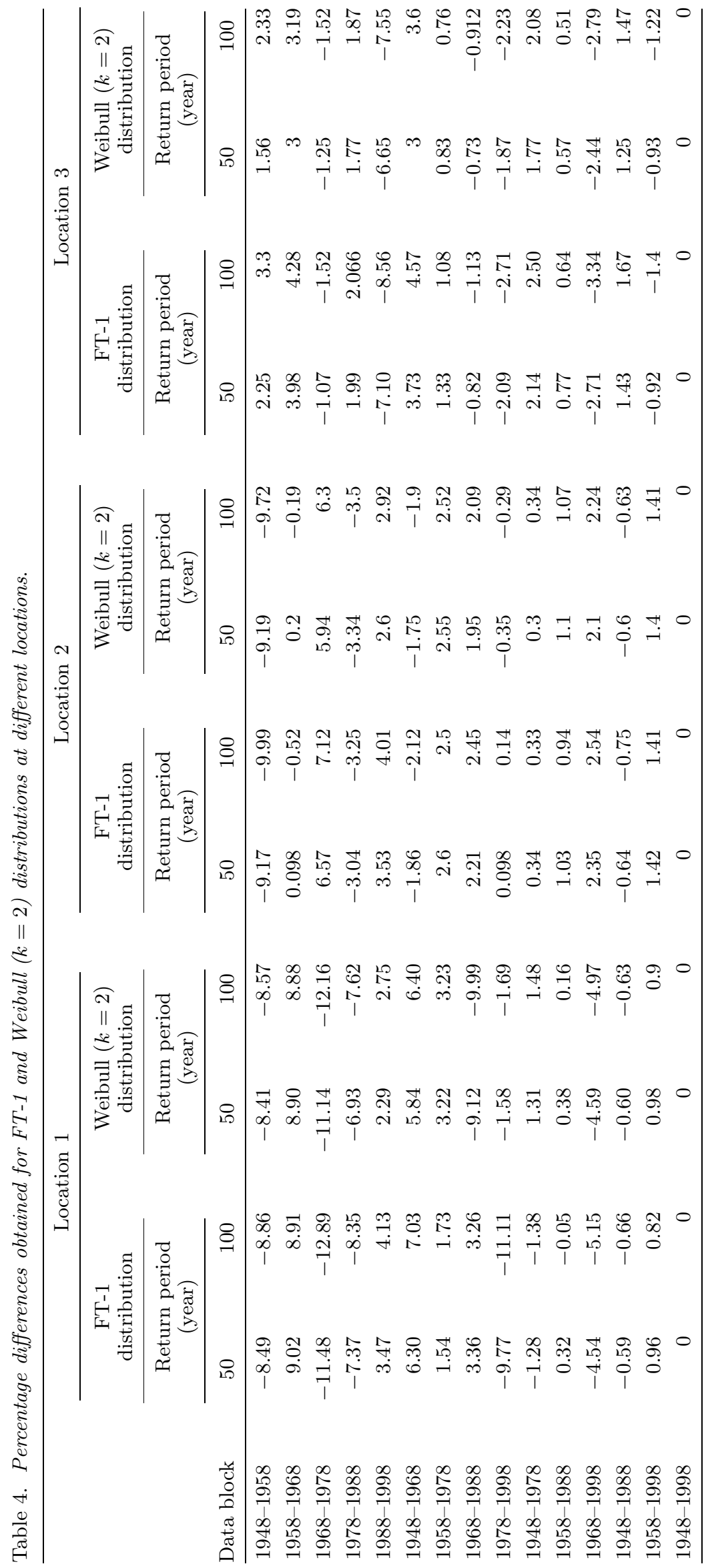



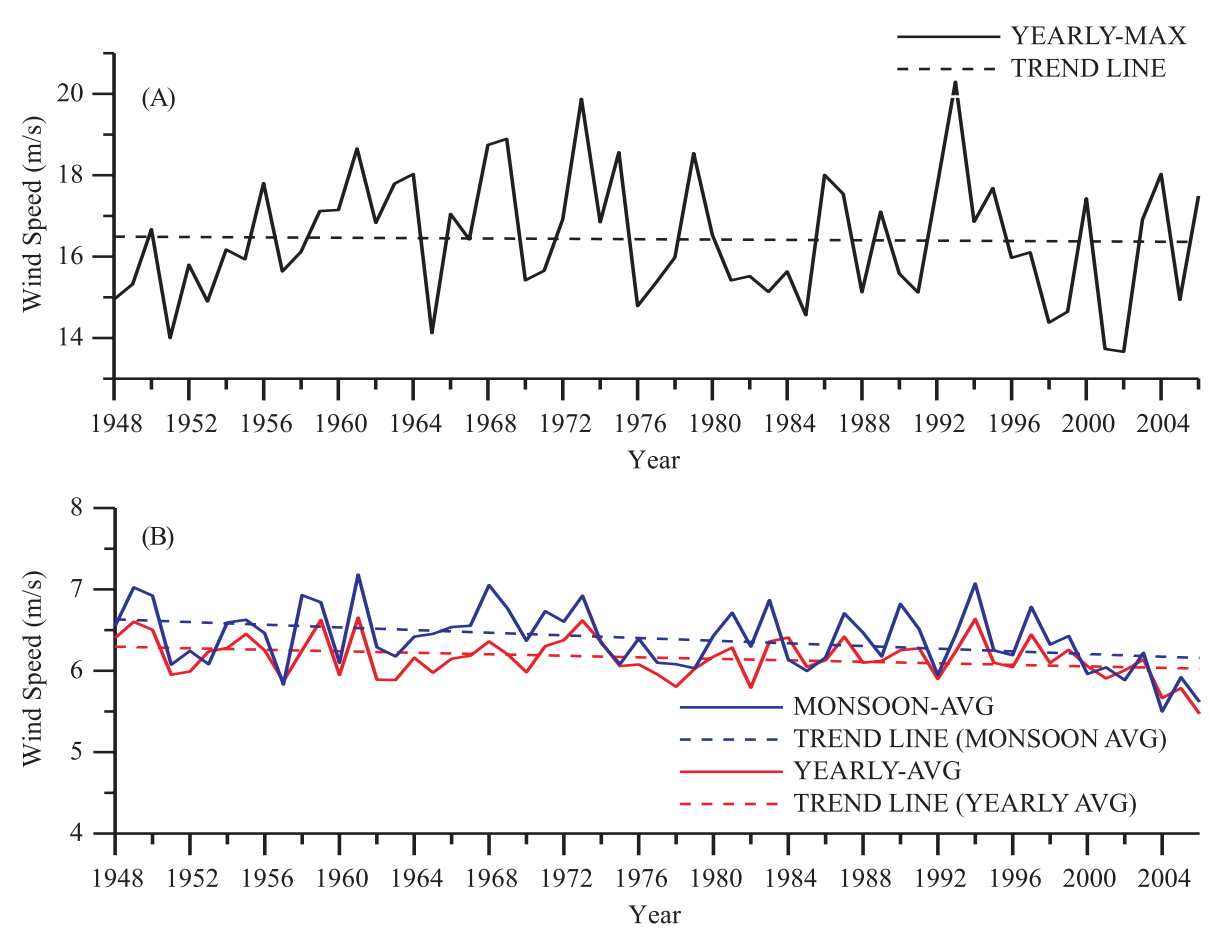

Figure 9. Graph showing interannual variability of (A) yearly maximum wind speed and (B) average monsoon wind speed and the yearly average wind speed for the location off Visakhapatnam.
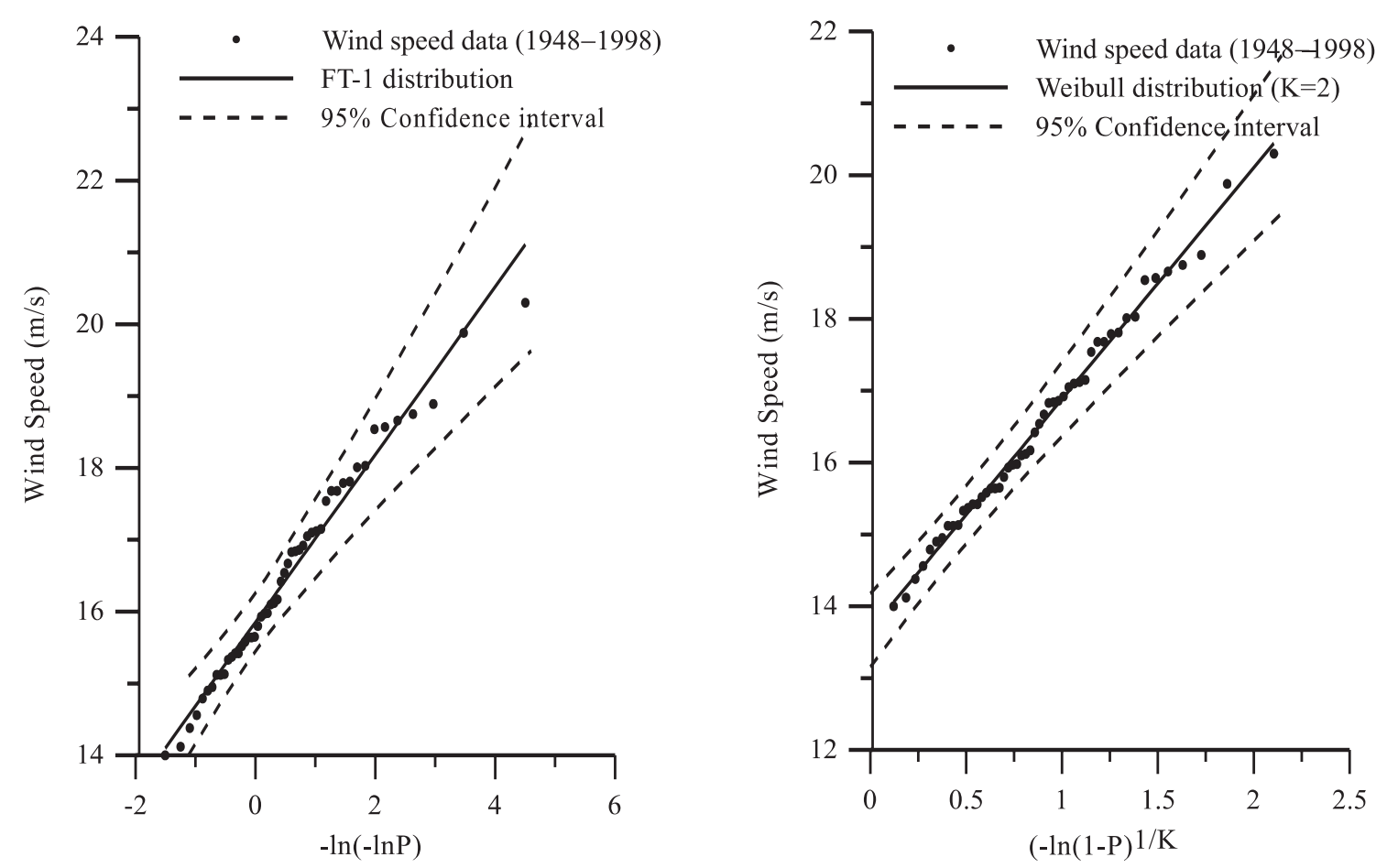

Figure 10. FT-1 and Weibull distributions $(k=2)$ applied to the yearly maximum wind data during 1948 to 1998 for the location off Visakhapatnam.

$(k)$ is generally close to 2 throughout the extra tropics. Previous studies by Pavia and Obrien (1986) and Isemer and Hasse (1991) observed that shape parameters are having high values in regions where strong and steady winds frequently occurs. In the present case, the distributions with shape parameter $k=2$ shows best fitting compared to other distributions. 

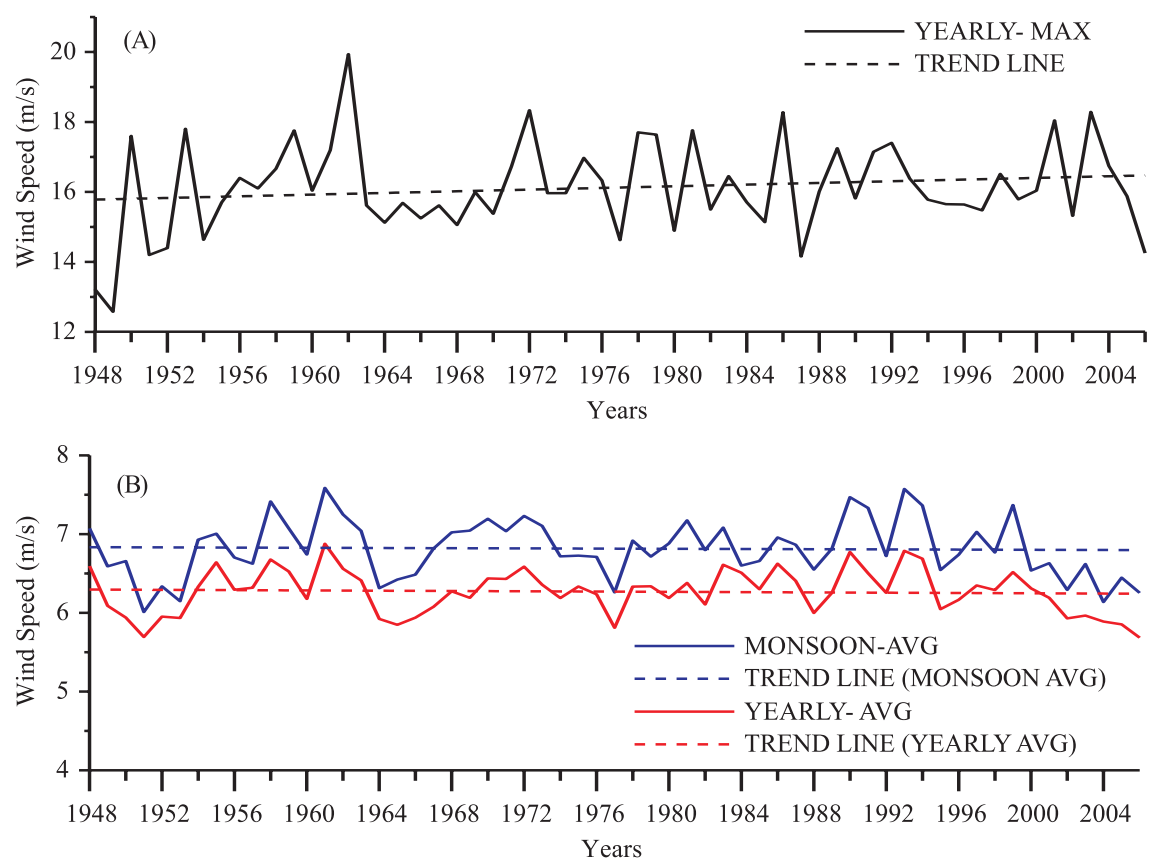

Figure 11. Graph showing interannual variability of (A) yearly maximum wind speed and (B) average monsoon wind speed and the yearly average wind speed for the location off Machilipatnam.
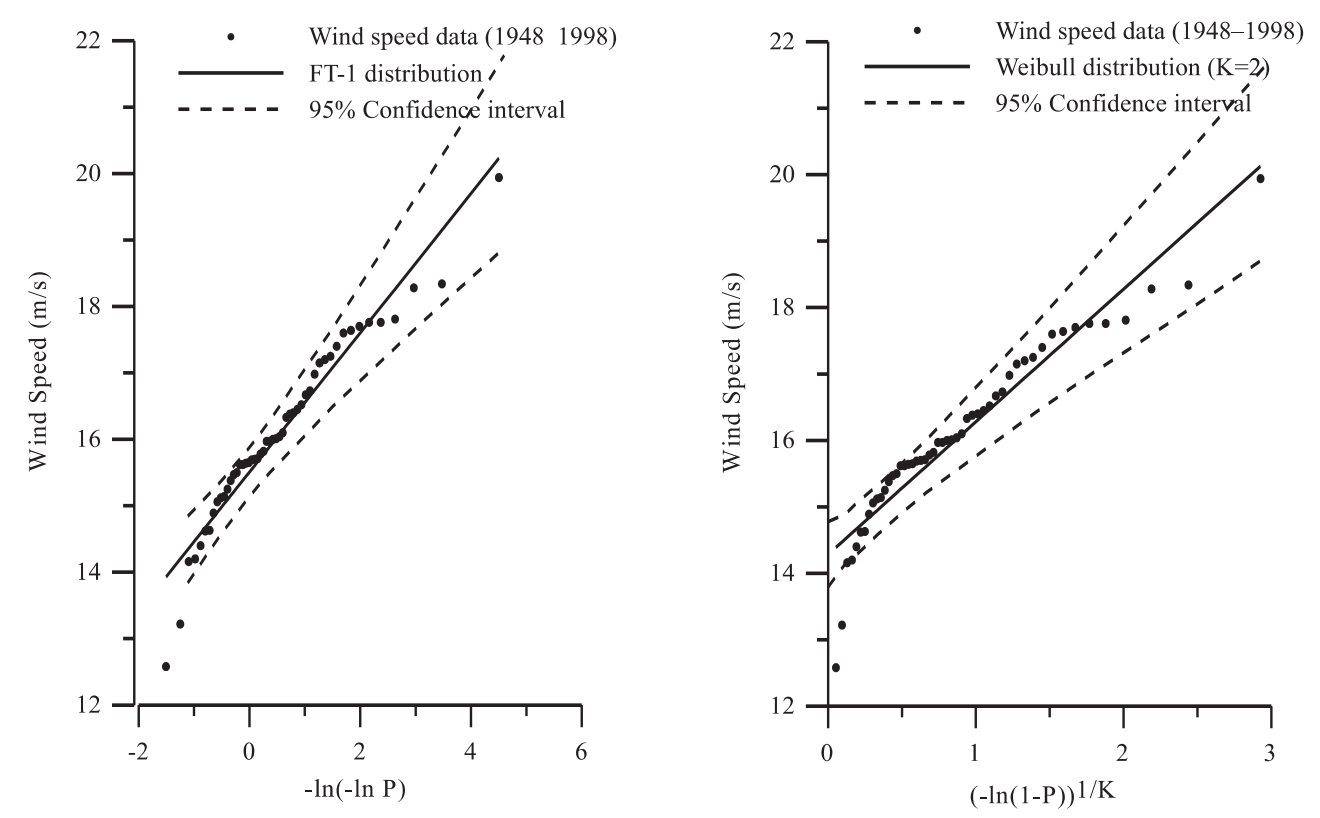

Figure 12. FT-1 and Weibull $(k=2)$ distributions applied to the yearly maximum wind data during 1948 to 1998 for the location off Machilipatnam.

\section{Discussion}

It was seen from the above analysis that there is no significant increase in the long term wind speeds. At location 3 (off Machilipatnam), a slight increase in annual wind speed $\left(1.2 \mathrm{~cm} \mathrm{~s}^{-1}\right.$ per year $)$ was observed (figure 11). At location 1 off Goa, the observed wind speeds were lower compared to the locations off Visakhapatnam and off Machilipatnam. This was because of its location in the Arabian Sea where the storm events were less compared to that of Bay of Bengal. Caires et al (2004) found in the seasonal analysis during July to September that there was negative (decreasing) trends in the Arabian Sea as low as $-1.9 \mathrm{~cm}$ per year in wave height. The decreasing trend in wind 

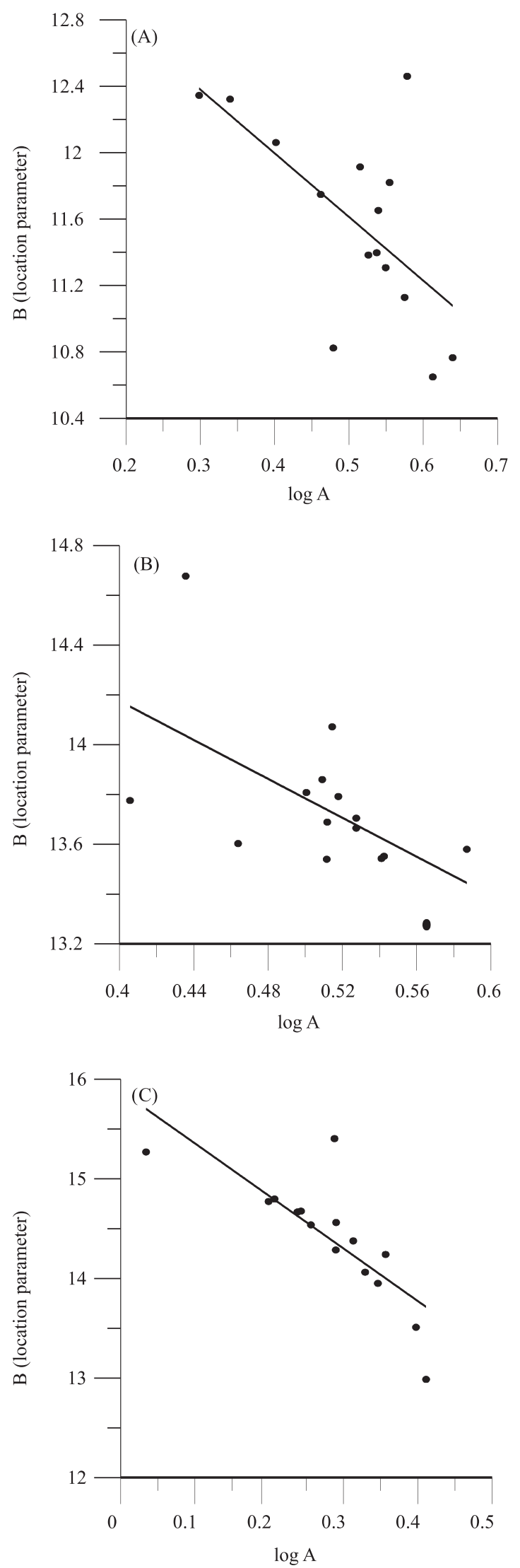

Figure 13. Variation of location parameter versus logarithm of scale parameter of Weibull distribution $(k=2)$ for the yearly maximum wind data during 1948 to 1998 (A) for the location off Goa, (B) for the location off Visakhapatnam and (C) for the location off Machilipatnam. speed observed is in line with the observation on wave height. At location 2, there is neither increasing nor decreasing trend, while at location 3 , there is a slight increasing trend in the inter-decadal variability. As already discussed, wind speeds occurred at Visakhapatnam was highest among the locations studied.

Here in this study, classical annual maximum (AM) was used for the estimation of extreme winds and the distribution schemes of FT-1 and Weibull were used. Different epochs were considered and from the largest epochs (40 to 50 years), corresponding long-term extreme wind speed events were estimated. In the case of off Goa, the estimated extreme wind speeds were observed as lower compared to that off Visakhapatnam and off Machilipatnam. For Visakhapatnam, the observed wind speeds were high and so the estimated extreme wind speeds were also high. Correlation coefficient of 1 was found in the case of Weibull with $k=2$ and the extreme wind speeds for 100 years return period was $20.64 \mathrm{~m} \mathrm{~s}^{-1}$. Monahan (2006) found that the Weibull distribution was a reasonably accurate approximation of the probability distribution of sea surface wind speeds on both a global and a local scale which was consistent with the results of earlier studies (Hennessey 1977; Justus et al 1978; Conradsen et al 1984; Isemer and Hasse 1991; Deaves and Lines 1997; Pang et al 2001). Xiao et al (2006) found that both type I (Gumbel) and type III (Weibull $k=2$ ) distributions give better fit with the empirical data. In the case off Machilipatnam, the estimated extreme winds were higher similar to that of Visakhapatnam. Since NCEP data used in the present study which underestimates the cyclone winds, the wind speed values presented in the paper cannot be used in design of the structures.

\section{Conclusion}

The study shows the inter-decadal variability of extreme winds in selected locations (off Goa, Visakhapatnam and Machilipatnam) in the north Indian Ocean. From the primary qualitative analysis it was seen that there is no significant increasing trend in extreme wind speeds in any of the locations studied. At location 1 (off Goa), a gradual decreasing trend of $-1.3 \mathrm{~cm} \mathrm{~s}^{-1}$ per year was obtained. A slight increasing trend of $1.2 \mathrm{~cm} \mathrm{~s}^{-1}$ per year was obtained in the case of Machilipatnam (location 3). For the case of Visakhapatnam (location 2), neither decreasing nor increasing trend was found.

From the extreme wind speed analysis for these locations, the wind speed value for the return period of 100 years was high for the location off 
Visakhapatnam followed by location off Machilipatnam. The study shows that Weibull distribution with shape parameter 2 fits the annual maximum wind data better than FT-1 distribution.

\section{Acknowledgements}

The authors thank the Director, NIO, Goa for encouragement and the facilities provided for the study. Authors thank the two anonymous reviewers for critical reviews and suggestions that improved the paper. This paper is NIO contribution no. 4797.

\section{References}

Allan J C and Komar P D 2000 Are ocean wave heights increasing in the eastern North Pacific?; EOS 81(47) 561, 566-567.

Bacon S and Carter D J T 1993 A connection between mean wave height and atmospheric pressure gradient in the North Atlantic; Int. J. Climatol. 13 423-436.

Bouws E, Jannink D and Komen G J 1996 The increasing wave height in the North Atlantic Ocean; Bull. Amer. Meteor. Soc. 77 2275-2277.

Caires S and Swail V 2004 Global wave climate trend and variability analysis; In: Proc. Eighth Int. Workshop on Wave Hindcasting and Forecasting, Oahu, Hawaii, U.S. Army Engineer Research and Development Center's Coastal and Hydraulics Laboratory and Cosponsors, CD-ROM, Al.

Carter D J T and Draper L 1988 Has the North East Atlantic become rougher?; Nature 332494.

Conradsen K, Nielsen L and Prahm L 1984 Review of Weibull statistics for estimation of wind speed distributions; J. Climate Appl. Meteor. 23 1173-1183.

Cook N J and Harries R I 2001 Discussion on application of the generalized Pareto distribution to extreme value analysis in wind engineering (eds) Holmes J D and Moriarity W W, J. Wind Eng. Ind. Aerodyn. 89 $215-224$.

Deaves D and Lines I 1997 On the fitting of low mean wind speed data to the Weibull distribution; J. Wind Eng. Ind Aerodyn. 66 169-178.

Dube S K, Rao A D, Singha P C, Murthy T S and Bahulayan N 997 Storm surge in Bay of Bengal and Arabian Sea: The problem and its prediction; Mausam $48283-304$.

Gray W M 1985 Tropical Cyclone Global Climatology; WMO Technical Document WMO/TD No. 72, WMO, Geneva, Switzerland, 1 3-19.

Goswami B N and Sengupta D 2003 A note on the deficiency of NCEP/NCAR re-analysis surface winds over equatorial Indian Ocean; J. Geophys. Res. 108 C4, doi: 10.1029/2002JC001497.
Gower J F R 2002 Temperature, wind, and wave climatologies, and trends from marine meteorological buoys in the northeast Pacific; J. Climate 15 3709-3718.

Gumbel E J 1958 Statistics of Extremes (New York: Columbia Univ. Press) 375 pp.

Hennessey J P 1977 Some aspects of wind power statistics; J. Applied. Meteor. 16 119-128.

Isaacson M and Mackenzie N G 1981 Long-term distribution of ocean waves: A review; J. Waterway Port Coastal Ocean Division; American Soc. Eng. 107 93-109.

Isemer H and Hasse L 1991 The scientific Beaufort equivalent scale: Effects on wind statistics and climatological air-sea flux estimates in the north Atlantic Ocean; J. Climate 4 819-836.

Justus C G, Hargraves W R, Mikhail A and Graber D 1978 Methods for estimating wind speed frequency distributions; J. Appl. Meteor. 17 350-353.

Kalnay E et al 1996 The NCEP/NCAR 40-year reanalysis project; Bull. Amer. Meteor. Soc. 77 437-471.

Monahan A H 2006 The probability distribution of sea surface wind speeds. Part I: Theory and sea winds observations; J. Climate 19 497-520.

Muir L R and EI-Shaarawi A H 1986 On the calculation of extreme wave heights: A review; Ocean Engineering 13(1) $93-118$.

Naess A 1998 Estimation of long return period design values for wind speeds; J. Eng. Mech. 124(3) 252-259.

Pang W K, Forster J J and Troutt M D 2001 Estimation of wind speed distribution using Markov chain Monte Carlo techniques; J. Appl. Meteor. 40 1476-1484.

Parekh A, Sharma R and Sarkar A 2007 A comparative assessment of surface wind speed and sea surface temperature over Indian Ocean by TMI, MSMR, and ERA-40; J. Atmos. Oceanic Technol. 24 1131-1142.

Pavia E G and O'Brien J J 1986 Weibull statistics of wind speed over the ocean; J. Clim. Appl. Met. 25 1324-1332.

Pugh D T 1987 Tides, Surges and Mean Sea-Level; (Hoboken, N. J.: John Wiley) 472 pp.

Rao Y R and Premkumar K 1998 A preliminary analysis of meteorological and oceanographic observations during the passage of a tropical cyclone in Bay of Bengal; Tech. Note NIOT-NDBP-TR-001/98, National Institute of Ocean Technology, Tamil Nadu, India.

Senan R, Anitha D S and Sengupta D 2001 Validation of SST and wind speed from TRMM using north Indian Ocean moored buoy observations; CAOS Report 2001 $A S 1$, Centre for Atmospheric Sciences, Indian Institute of Science, Bangalore, India.

Sengupta D, Joseph P, Senan R and Suresh Kumar G 1999 Validation NCEP daily surface winds over the north Indian Ocean; CAOS Report 99AS1, Centre for Atmospheric Sciences, Indian Institute of Science, Bangalore, India.

Singh O P, Ali Khan T M and Rahman M S 2001 Has the frequency of intense tropical cyclones increased in the North Indian Ocean? Curr. Sci. 60 575-580.

Streeter V L, Wylie E B and Bedford K W 1998 Fluid Mechanics; McGraw-Hill, Singapore, 1-740.

Xiao Y Q, Li Q S, Li Z N, Chow Y W and Li G Q 2006 Probability distributions of extreme winds and its occurrence interval; Eng. Struct. 28 1173-1181. 